Acta Poetica 28 (1-2)

PRIMAVERA-OTOÑO

2007

\title{
Baudelaire y Julio Cortázar. Pasajeros de la experiencia benjaminiana
}

\author{
Elsa Rodríguez Brondo
}

\begin{abstract}
Walter Benjamin analizó la figura de Charles Baudelaire bajo la mirada de la modernidad en "Sobre algunos temas en Baudelaire". De este ensayo retomamos la noción benjaminiana de pobreza de experiencia para observar la representación femenina en tres momentos literarios: el roman cortés, la poesía de Baudelaire y la narrativa de Julio Cortázar.
\end{abstract}

Walter Benjamin analyzed Charles Baudelaire's figure under the perspective of Modernity in "Sobre algunos temas en Baudelaire". This article retook the benjaminian's notion of poverty of experience to observe the women representation in three literary moments: the court romance, the poetry of Baudelaire and the narrative of Julio Cortázar. 

Acta Poetica $28(1-2)$

PRIMAVERA-OTOÑO

2007

Elsa Rodríguez Brondo

FFyL, UNAM

\section{Baudelaire y Julio Cortázar. Pasajeros de la experiencia benjaminiana}

El siglo XIX trajo consigo a la absoluta modernidad que ya se atisbaba a finales del siglo XVIII. Las ciudades cosmopolitas se poblaron de enormes centros de producción y las masas de obreros y empleados comenzaron sus travesías cotidianas, más sombrías y más solitarias que aquellas emprendidas por los incansables buscadores de maravillas en tierras ignotas de los libros de viaje de esa época. En la ciudad luz, las obras del metro se concluyeron en 1900. A la una de la tarde del 19 de julio se hizo el primer viaje por el subsuelo parisino. En París, el siglo veinte, recién inaugurado, dio la respuesta al caos vial que había producido el proceso de industrialización en el siglo anterior, dando espacio a la soledad colectiva en tránsito, propiedad exclusiva de las grandes ciudades. Espacio, quizá simbólico, del hombre y la mujer modernos.

En la literatura del escritor argentino Julio Cortázar la presencia del metro parisino es una constante, en ocasiones como contexto y en otras como punto focal, razón narrativa. En su relato "Manuscrito hallado en un bolsillo", del libro Octaedro de 1974, se desarrolla un viaje en las profundidades del subte- 
rráneo, escenario de un juego amoroso a la vez que estructura de la naturaleza misma del relato.

Ahora que lo escribo, para otros esto podría haber sido la ruleta o el hipódromo, pero no era dinero lo que buscaba, en algún momento había empezado a sentir, a decidir que un vidrio de ventanilla en el metro podía traerme la respuesta, el encuentro con una felicidad, precisamente aquí donde todo ocurre bajo el signo de la más implacable ruptura (Cortázar 1974, 51).

El metro es el lugar del viaje cotidiano, de un viaje que se distingue de los que, a fuerza de tiempo y de ese compartir con la misma gente los avatares de una travesía, propician una complicidad fuerte y transitoria. Las estancias en cubierta, los saludos amables en las cenas de abordo, los juegos de azar compartidos en el camarote, propios de los viajes en barco, o las largas caminatas por los vagones de un tren-hotel, en donde se ve pasar el paisaje o se experimenta el ritmo del recorrido en el cuerpo mientras se duerme en el camarín, están vedados a la población efímera del metro. Las estaciones se suceden llevando y trayendo a nuevos pasajeros. No hay complicidad, las miradas y los cuerpos chocan violentamente, para luego encontrar refugio y resarcirse en el techo o en una hoja de periódico. El metro, "donde todo ocurre bajo el signo de la más implacable ruptura", es el lugar de la indagación amorosa dibujada a placer por el personaje cortazariano.

Mi regla del juego era maniáticamente simple, era bella, estúpida y tiránica, si me gustaba una mujer, si me gustaba una mujer sentada frente a mí, si me gustaba una mujer sentada frente a mí junto a la ventanilla, si su reflejo en la ventanilla cruzaba la mirada con mi reflejo en la ventanilla, si mi sonrisa en el reflejo de la ventanilla turbaba o complacía o repelía al reflejo de la mujer en la ventanilla, si Margrit me veía sonreír y entonces Ana bajaba la cabeza y empezaba a examinar apli- 
cadamente el cierre de su bolso, entonces había juego (Cortázar 1974, 54).

El juego del caballero se entabla en el ámbito de la convivencia impersonal del metro: intentar establecer en la mirada un vínculo que quizá, sólo quizá como se verá, sea permanente. Forzar los mecanismos de aislamiento, aunque el juego y su elemento azaroso no puedan dejar un intersticio a las decisiones, es un intento por rescatarse de un mundo en donde lo excepcional pasa de largo, porque nadie o sólo muy pocos lo notan. El riesgo es abismal cuando la felicidad, por no decir el amor, está en la mesa de las apuestas; cuando el erotismo, fuerza vital, se pone a prueba en un lugar parecido al infierno, profundo y mortal, y se busca a la dama en las condiciones más adversas.

Cortázar escribió un texto que habla de su relación con el metro de París: "Bajo nivel”. En él recuerda el primer subterráneo de su vida, el bonaerense. De esa ciudad cuya apariencia es más europea que americana, Cortázar transita a otra que fue la capital de las vanguardias.

Cuando llegué a París en 1949, trayendo como brújula la literatura francesa, Charles Baudelaire era mi gran psicopompo; el primer día quise conocer el Hôtel Pimodan, en la isla SaintLouis, y al preguntar por el metro que me llevaría a orillas del Sena, el hotelero me indicó la línea y agregó: "Es fácil, no hay más que una correspondencia". En ese momento mi memoria volvía una y otra vez al célebre soneto de Baudelaire (Cortázar 1996, 10).

Es en ese París, acotado por los sonetos de Baudelaire, donde Cortázar escribe "Manuscrito...". Su personaje cree evadir la "terca hemorragia de milagros rotos"1 con un juego amoroso, que a su vez reproduce la odisea del chevalier del roman medieval en las posibilidades aleatorias de los túneles.

\footnotetext{
${ }^{1}$ Verso del poema "La música de las esferas” de Jorge Fernández Granados.
} 
Porque no basta que Margrit (reflejo), que es a la vez Ana (la chica sentada frente a él) rescate una sonrisa en la ventanilla. No basta que se traicione la soledad del vagón, es necesario que la mujer elegida, su dama, a su vez elija (sin saberlo) estaciones, correspondencias y direcciones que el jugador, caballero andante, ha impuesto a su aventura. ¿O es el propio metro el que las ha determinado y se impone inexorablemente sobre sus visitantes? ¿Hay algún modo de escapar al diseño de los itinerarios o a la oscuridad de los túneles que vuelve uniformes todos los paisajes? Ese diseño, que las mismas necesidades de la modernidad imponen a la masa impersonal de las ciudades, antes que en Cortázar, está dibujado en la obra de Charles Baudelaire y aquí tendremos que reconocer una correspondencia entre los dos escritores.

\section{Correspondencia benjaminiana}

Lo típico de la poesía de Baudelaire reside en que las imágenes de la mujer y de la muerte están compenetradas de una tercera, la imagen de París.

WALter Benjamin, "Baudelaire o las calles de París"

Para Walter Benjamin, Baudelaire encarna el filo que corta la concepción del poeta que hasta ese momento existía. Es el último autor que ha registrado un éxito masivo — sus contemporáneos, Verlaine y Rimbaud, han limitado su territorio a los iniciados. En "Sobre algunos temas en Baudelaire" (1939), ${ }^{2}$ Benjamin plantea que las razones de este parteaguas se deben a la modernidad y a que Baudelaire se ha integrado a esa modernidad a costa de concebir una poesía que alegoriza una

\footnotetext{
${ }^{2}$ Publicado originalmente en Zeitschrift für Sozialforschung.
} 
experiencia empobrecida. La vida de la producción en masa ha cobrado sus víctimas en una multitud cuya capacidad para asimilar la experiencia está atrofiada. Su trabajo ya no es fabricar una pieza artesanal completa, sino ser obrero en una de las tantas fases de la hechura de un producto; la información que circula en los periódicos a partir de la época de Baudelaire está disociada de la vida de sus lectores; es la era de los grandes tirajes, de las noticias aisladas, del sensacionalismo. La fotografía, en ese proceso doloroso del daguerrotipo, consiste en mirar a la cámara, a una máquina, durante interminables minutos, no ya al artista, no ya a los ojos que devuelven la mirada. En suma, las grandes ciudades del XIX han creado un sistema de vida que en apariencia avanza a un progreso sin precedentes; su estela vertiginosa, en cambio, es una existencia saturada de experiencias rotas e intermitentes, que niegan la singularidad de la experiencia a cada individuo que forma el contingente amorfo de las masas.

A ciertas horas, el hormigueo humano recorre las calles parisinas, los obreros a las fábricas, los empleados a sus oficinas. Es un viaje masificado pero no compartido; el sujeto se cuida de no ser tocado por los otros, para no ser despertado de su letargo; mantiene la mirada en un punto lejano, apresura el paso, entre hombros y codos, porque el tiempo lo rebasa sin gentileza. Esta visión es de Benjamin, que a su vez ha recuperado de la observación de Engels ${ }^{3}$ y de Poe $^{4}$ quienes en su opinión son

\footnotetext{
3 "Engels hace de esta masa [que] en su obra juvenil preludia, aunque tímidamente, uno de los temas marxistas. En Situación de las clases trabajadoras en Inglaterra dice: '[...] Ya el hervidero de las calles tiene algo de desagradable, algo contra lo cual la naturaleza humana se rebela. [...] Y sin embargo se adelantan unos a otros apuradamente, como si no tuvieran nada en común, nada que hacer entre ellos; sin embargo, la única convención que los une, tácita, es la de que cada cual mantenga la derecha al marchar por la calle, a fin de que las dos corrientes en la multitud, que marchan en direcciones opuestas no choquen entre sí; sin embargo, a ninguno se le ocurre dignarse a dirigir a los otros aunque sólo sea una mirada" (en Benjamin 1999, 16).

4 "En Poe [en su relato "El hombre de la multitud"] la multitud de Londres aparece tan tétrica y confusa como la luz de gas en la cual se mueve. Ello no es válido
} 
los primeros en dibujar la fisonomía de las multitudes. Esta secuencia de las calles del siglo XIX pareciera el retrato actual de una estación de metro, como si la visión callejera se hubiera terminado de esconder, avergonzada, en los subterráneos del siglo veinte, imagen del relato de Cortázar, y dejara de circular a cielo abierto.

En este entorno asediado por los más disímiles estímulos, en su mayoría violentos, Benjamin también dialoga con Freud y la noción surrealista del golpe emocional, el shock. Sobre todo con la estrenada facultad del hombre moderno para recibir información indiscriminada del mundo exterior y, a la vez, filtrarla toda a través de la conciencia, aunque al final ésta no pueda distinguir entre una y otra, no pueda privilegiar a una información sobre otras. La experiencia atrofiada en la modernidad estará tamizada, uniformada, desvinculada y desprovista de aura. ${ }^{5}$

La poesía Baudeleriana, Baudelaire mismo, se ha convertido en la depositaria de esos estímulos circundantes, "[Baudelaire] se ha hecho cargo de detener los shocks, con su propia persona espiritual y física, de donde quiera que éstos provengan" (Benjamin 1999, 14). Las multitudes no están literalmente en su obra, son lo que la anima, lo que está por antonomasia como presencia unívoca de la existencia poética moderna.

Baudelaire, concluye Benjamin,

sólo para la gentuza que desemboca en la noche desde su cuevas: La clase de los empleados superiores [también]" (en Benjamin 1999, 20).

${ }^{5}$ En el sentido benjaminiano, desarrollado en La obra de arte en la época de su reproductibilidad técnica: "Conviene ilustrar el concepto de aura, que más arriba hemos propuesto para temas históricos, en el concepto de un aura de objetos naturales. Definiremos esta última como la manifestación irrepetible de una lejanía (por cercana que pueda estar). Reposando en una tarde de verano, seguir la línea montañosa en el horizonte o la extensión de la rama que echa su sombra sobre aquel que reposa, eso quiere decir respirar el aura de estas montañas, de esta rama. Con ayuda de esta descripción resulta fácil entender el condicionamiento social de la actual decadencia del aura. Se basa en dos condiciones que están conectadas, lo mismo la una que la otra, con el surgimiento de las masas y la intensidad creciente de sus movimientos" [subrayados míos] (Benjamin 2003, 47). 
Ha mostrado el precio al cual se conquista la sensación de la modernidad: la disolución del aura a través de la 'experiencia' del shock. La comprensión de tal disolución le ha costado caro. Pero es la ley de su poesía. Su poesía brilla en el cielo del Segundo Imperio como "un astro sin atmósfera" (Benja$\min 1999,41)$.

Si la poesía de Baudelaire ha pagado un alto precio por "la conquista de la sensación de la modernidad", el relato "Manuscrito hallado en un bolsillo" de Cortázar pretende, por el contrario, sobrepasar los estímulos intermitentes para intentar llegar a una experiencia que escape de su pobreza, en el mismo terreno que Baudelaire ha colocado su mirada. Elegir el metro como lugar de una experiencia amorosa será retar a la modernidad misma, pero el reto también estará unido a la relación con la imagen femenina, empobrecida en la mirada masculina desde el medioevo.

Los romans medievales colocaron en sus historias a la figura femenina que ya había sido construida en las primeras formas líricas de los trovadores. Se trataba de poner en marcha, en los actos (textuales), la búsqueda de los favores y el amor de una dama. En esa búsqueda plena de obstáculos estaba en realidad el sentido de todo el relato. En la lógica del roman resultaría imposible imaginar a una mujer noble entregando su alma y su cuerpo a un caballero que no hubiese cumplido con el juego de sacrificio que él mismo se imponía. ${ }^{6}$ En los romans la figura masculina busca a través del viaje. Desplaza sus aventuras por bosques, mares y castillos. Su juego no es inerte o estático. En la narrativa caballeresca medieval los viajes son un tránsito. No hay un relato del gozo del camino, del paisaje, sino de las aventuras que se han de correr para llegar a un fin. Esas aventuras se viven en pos del más caro tesoro:

\footnotetext{
${ }^{6}$ En El caballero de la carreta de Chrétien de Troyes es Lanzarote quien se aboca a rescatar a Ginebra de Meleagante.
} 
la dama. Pero el trofeo a tantas vicisitudes apenas ocupa espacios de alabanzas y epítetos, descripciones físicas que se antojan el catálogo cerrado de un modelo; la dama desdeña, pide o acepta en lugares puntuales del relato. ${ }^{7}$ El caballero elige, persigue, se aventura, lucha y viaja para alcanzar con sus trabajos los favores de Midons (mi señora).

La imagen femenina en la literatura cortés de la Edad Media plantea uno de los estereotipos ${ }^{8}$ de lo femenino que configura un modelo de características cerradas y limitadas del género. En este sentido, la imagen femenina en la literatura está empobrecida mucho antes que la experiencia del sujeto, que Benjamin ubica en la modernidad.

Dirección desventura, correspondencia alegórica

A una transeúnte

La calle atronadora aullaba en torno mío.

Alta, esbelta, enlutada, con un dolor de reina

Una Dama pasó, que con gesto fastuoso

recogía, oscilantes, las vueltas de sus velos,

Agilísima y noble, con dos piernas marmóreas.

De súbito bebí, con crispación de loco,

Y en su mirada lívida, centro de mil tornados,

El placer que aniquila, la miel paralizante

Un relámpago. Noche. Fugitiva belleza

Cuya mirada me hizo, de un golpe renacer.

¿Salvo en la eternidad, no he de verte jamás?

${ }^{7}$ Cf. Erec y Enid de Chrétien de Troyes.

8 "Término con el que se alude a expresiones verbales convertidas en clichés, a tipos o personajes heredados de la tradición, cuyos gestos, comportamientos y lenguaje se repiten mecánicamente, y a temas y situaciones tipificadas que reaparecen reiterativamente en diferentes épocas" (Estébanez Calderón, 370). 
¡En todo caso lejos, ya tarde, tal vez nunca!

Que no sé a dónde huiste, ni sospechas mi ruta,

¡Tú a quien hubiese amado. Oh tú, que lo supiste!

Charles Baudelaire, Las flores del mal

El poema "A la transeúnte" (1860) recuerda el comienzo de la Vida Nueva de Dante. El encuentro visual con una dama (como así nombran los dos a una mujer) provoca un relámpago en uno: "Un relámpago. Noche. Fugitiva belleza / Cuya mirada me hizo, de un golpe renacer" (Baudelaire, 124) y un temblor en el otro: "en aquel punto digo en verdad que el espíritu de la vida que mora en la cámara secretísima del corazón comenzó temblar" (Dante, 537). Los dos encuentros son fruto de la literatura, los dos comparten la aparición de esa dama tantas veces construida, imaginada. ¿La experiencia amorosa es la misma? Para Benjamin el éxtasis del poeta citadino "no es tanto un amor a primera vista como a 'última vista'. Es una despedida para siempre, que coincide en la poesía con el instante del encanto" (Benjamin 1999, 19). Para Dante será el comienzo de una invención amorosa de largo alcance, que abarcará no una obra monumental sino su propia vida, en tanto que Baudelaire introduce el inexorable nunca en los últimos versos. Una instantánea que la multitud ha regalado al poeta, como una flor en manos de quien la sabe muerta. El relámpago baudeleriano para Benjamin "no es la beatitud de aquel que se siente invadido por el eros en todas las cámaras de su particular idiosincrasia, sino más bien la turbación sexual que puede sorprender al solitario" (Benjamin 1999, 19).

A pesar de compartir el desencanto benjaminiano, los ecos del amor cortés se han infiltrado en el discurso poético de Baudelaire. La dama ha pasado de largo, ha provocado el instante, aunque para el que ha depauperado su experiencia todo haya sucumbido en el umbral del enamoramiento. La mujer sigue 
siendo objeto de la mirada; ahí se construye con los códigos que la invención medieval prodigó. En la corte del siglo XII o despojada de su aura, inserta entre los caminantes de la ciudad moderna, la dama invoca su imaginaria presencia, invocando también la naturaleza originaria de esa mirada.

Cortázar busca en "Manuscrito hallado en un bolsillo" traspasar el shock baudeleriano. Extender un puente entre el amor cortés: el que elige a una dama para ser regalada con los homenajes del caballero, de un trovador exacerbado por su educación sentimental, y ese amor reelaborado por el romanticismo y la modernidad en donde la dama se bifurca entre la fragilidad personificada y La belle dame sans merci. Una tercera representación femenina en la literatura se filtra lo mismo en la fragilidad que en la crueldad de las mujeres-personaje en las postrimerías del siglo XIX y es la imagen, la ausencia como presencia, el estar fugaz de lo femenino que lo mismo puede aparecer en un cuadro ("El retrato ovalado" de Edgar Allan Poe), en un momento teatral (El retrato de Dorian Gray de Óscar Wilde) o en esa mirada pasajera en "A una transeúnte" de Baudelaire que detonan el empecinamiento amatorio.

La inclusión de la mujer en la vida productiva de las capitales del mundo, lejos de producir un cambio en las páginas masculinas - y aun en las de las autoras de la época-, deviene un distanciamiento frente a la otra absolutamente otra. Ahí está la imagen, quizá de una muerta como en el relato "El retrato ovalado" de Poe; ahí está la fascinación de Dorian por una actriz que después de su representación es rechazada por encarnar lo prosaico en la novela de Wilde; ahí está como creación mágica, carente de alma, voluntad y corazón, en la Eva futura de L'Isle Adam. Esta figura es la sombra, el fantasma útil, el dummy, ${ }^{9}$ la imposibilidad material necesaria

\footnotetext{
9 "An object made to look like and take the place of a real thing". Un objeto hecho a imagen y semejanza de un objeto real que ocupa su lugar [la traducción es mía] (Dictionary of contemporary English, London, Logman, 1990).
} 
para crear una distancia paradójica: en la medida de esa imposibilidad se ama y se desea. "De ese canto, de ese encanto, hay que mantenerse a distancia; hay que mantenerse a distancia de la distancia, y no sólo, como podría suponerse, para protegerse contra esa fascinación, sino también para experimentarla" (Derrida 1981, 33).

De esa tercera figura habla Baudelaire en su poema "A una transeúnte". Es apenas un instante en que se ha columbrado el amor en la mirada, el encuentro de Dante que esta vez no pervive más allá de su resplandor y es en la lectura latinoamericana de Cortázar, en "Manuscrito hallado en un bolsillo", la mirada que inicia, con la presencia ausente de la mujer, el juego de un amor imposible

Un juego, sin embargo, vital para el personaje que busca incesante, en las profundidades del metro, trascender el relámpago baudeleriano y el temblor de Dante, a través del mismo juego que inició la literatura medieval.

"La regla del juego era ésa, una sonrisa en el cristal de la ventanilla [del vagón] y el derecho de seguir a una mujer y esperar desesperadamente que su combinación [hacia otras estaciones] coincidiera con la decidida por mí antes de cada viaje" (Cortázar 1974, 55). El juego se rompe cuando decide seguir a una mujer hasta la superficie, abordarla y entablar con ella una tibia relación. Marie-Claude es el nombre de esta mujer de carne y hueso que encarna la posibilidad amorosa. Antes de ser Marie-Claude, el personaje había nombrado a la mirada femenina reflejada en la ventanilla como Margrit, y a la pasajera sentada frente a él, Ana. Una misma figura escindida entre reflejo y corporeidad que en la calle toma forma y voz. Pero esta ruptura del ritual entraña dos peligros: se han infringido las leyes del juego y del amor, los dos, uno mismo para el relato. Acercarse a una mujer puede destruir también el juego del eterno masculino. 
El encantamiento erótico dura exactamente el tiempo en que el enamorado es capaz de ver en su amada la imagen primigenia. El fin de esta dicha es inevitable, pues hasta la mujer más hermosa pierde su secreto, una vez poseída (Muschg, 514).

Para un jugador de póquer las pulsiones del deseo hacen incurable su ludopatía, para el jugador amoroso de Cortázar también lo son. El amor subterráneo, cuyo espacio está predestinado a la ruptura, no puede consentir una ruptura en sus azarosos itinerarios. No basta que Marie-Claude, la encarnación de su imaginario, sea el objeto elegido. Las arañas y el pozo llevan de nuevo su búsqueda a los terrenos de su intrincada telaraña del metro. Esta vez, para jugar de un modo suicida incluyendo a Marie-Claude, de rostro nítido, para entregarla al laberinto del minotauro e intentar hallarla, durante quince días, así más deseada y más amada.

La modernidad parece haber perdido la partida, el caballero ha decidido continuar su empresa como la que una vez emprendió Lanzarote del Lago en El Caballero de la carreta para recuperar a Ginebra, con la misma vehemencia con que Dante emprende el camino hacia la muerta Beatriz en la Divina comedia. El placer destructivo de buscar las interminables combinatorias de los recorridos, el azar que deja a más de uno sentado en una banca de las estaciones, esperando desesperanzado, son los enemigos. Derrotado el personaje de este viaje confiesa:

Porque todavía espero en este banco de la estación Chemin Vert, con esta libreta en la que una mano escribe para inventarse un tiempo que no sea solamente esa interminable ráfaga que me lanza hacia el sábado en que acaso todo habrá concluido, en que volveré solo y las sentiré despertarse y morder, sus pinzas rabiosas exigiéndome el nuevo juego, otras MarieClaudes, otras Paulas, la reiteración después de cada fracaso, el recomienzo canceroso (Cortázar 1974, 63). 
El título del relato es una clave para conocer el fin último del viaje, de lo que en inglés se aglutina en la palabra quest ${ }^{10}$ El buscador, se intuye, se tira bajo las ruedas del metro ${ }^{11}$ apagando la desazón y la pulsión de las arañas y el pozo (metáforas las dos del subterráneo). Hay algo lúcido y también turbio en el personaje de "Manuscrito hallado en un bolsillo". Podemos inferir, acaso, que intenta recuperar la experiencia amorosa única, singularizada, la que para Benjamin ha sufrido en su naturaleza la misma atrofia, el mismo empobrecimiento. Podemos también inferir que ha sido capaz de atisbar lo extraordinario que se oculta en lo prosaico de las ciudades y está dispuesto a develarlo. Pero la compulsión de esa búsqueda es un signo de la compulsión del jugador que narra Benjamin en sus notas sobre Baudelaire: "los jugadores se entregan en el juego [éste] se adueña de sus cuerpos y de sus almas, por lo cual incluso en su fuero interno, por fuerte que sea la pasión que los agita, no pueden obrar más que automáticamente" (Benjamin 1999, 27).

La avidez de jugar es el motor, la pasión proyectada en una mujer - lo extraordinario del encuentro amoroso- es sólo la inspiración del viaje. La estructura cortesana, la del amor trovadoresco, la del caballero, ha sobrevivido, reelaborado. ${ }^{12}$ Los personajes, el viaje, el posible encuentro, empobrecidos. Mas la dama pervive "Lo esencialmente lejano es inaccesible:

\footnotetext{
${ }^{10}$ A long search; an attempt to find something. Larga búsqueda; un intento por encontrar algo (Dicctionary of Contemporary English, Logman, England, 1990).

11 “ 'Manuscrito hallado en un bolsillo' [...] trata de un hombre que se impone una regla de juego en la búsqueda de una mujer y ganará o perderá según que esa mujer elija o no una determinada correspondencia. Él tiene que cumplir la regla y pierde. El título indica que se tiró bajo las ruedas del metro" (Cortázar en Yurkievich 1994, 71).

12 "Ya Kendrick ha estudiado la creación poética de los primeros trovadores como un 'juego" entre poetas que compiten a través de sus acrobacias verbales por el lugar del 'mejor poeta'. El objeto de este "juego del amor" no es conquistar a la dama, sino superar a los rivales en la manipulación de la palabra poética" (Azuela, 282).
} 
la inaccesibilidad es una característica esencial de la imagen del culto" (Benjamin 1999, 36). Tan depauperada como en la Edad Media, ella sigue siendo ese objeto fantasmal sujeto al devenir masculino, a las decisiones arbitrarias, al camino trazado, pero con el ingrediente decimonónico que ha producido una imagen femenina imposible de poseer. ${ }^{13} \mathrm{Si}$ esto no fuera suficiente para el desaliento, también el personaje masculino de Cortázar, masificado por la metrópoli, está sujeto a una ruta, una estación y un camino, ahí "donde todo ocurre bajo el signo de la más implacable ruptura", aquí.

\section{BIBLIOGRAFÍA}

Azuela, Cristina, "Apuntes para una discusión sobre la representación de la mujeres en la literatura medieval francesa: entre los trovadores y los fabliaux", en Jornadas Filológicas 1998. Memoria, México, UNAM, 1999.

Baudelaire, Charles, Las flores del mal, Madrid, Alianza, 1982.

Benjamin, Walter, "Sobre algunos temas en Baudelaire", en Ensayos escogidos, México, Ediciones Coyoacán, 1999.

— "Baudelaire o las calles de París", en Para una crítica de la violencia, México, Premiá, 1977.

- La obra de arte en la época de su reproductibilidad técnica, México, Itaca, 2003.

CORTÁZAR, Julio, "Manuscrito hallado en un bolsillo", en Octaedro, Madrid, Alianza, 1974.

- París, ritmos de una ciudad, Barcelona, Edhasa, 1981.

— "Bajo nivel", en La Jornada Semanal, núm. 53, México, La Jornada, 10 de marzo de 1996.

13 Por fantasmal, evanescente, escurridiza que recuerda a la imposibilidad de poseer a su dama de los trovadores provenzales, aunque esta imposibilidad sea distinta, no así en el roman cortés cuyo galardón era la posesión física de la dama. 
Dante, Alighieri, La divina comedia y Vida nueva en Obras completas de Dante Alighieri, Madrid, Biblioteca de Autores Cristianos, 2002.

Derrida, Jacques, Espolones. Los estilos de Nietzsche, Valencia, Pre-Textos, 1981.

Estébanez CALDERón, Demetrio, Diccionario de términos literarios, Madrid, Alianza, 2001.

MuschG, Walter, Historia trágica de la literatura. Literatura alemana, historia y crítica, México, FCE, 1965.

Yurkievich, Saúl, Julio Cortázar: mundos y modos, Madrid, Anaya, 1994. 
